\title{
What influences business academics' use of the Association of Business Schools' (ABS) list? Evidence from a survey of UK academics
}

Article

Accepted Version

Walker, J. T., Fenton, E., Salter, A. and Salandra, R. (2019) What influences business academics' use of the Association of Business Schools' (ABS) list? Evidence from a survey of UK academics. British Journal of Management, 30 (3). pp. 730747. ISSN 1467-8551 doi: https://doi.org/10.1111/14678551.12294 Available at https://centaur.reading.ac.uk/75771/

It is advisable to refer to the publisher's version if you intend to cite from the work. See Guidance on citing.

To link to this article DOI: http://dx.doi.org/10.1111/1467-8551.12294

Publisher: Wiley

All outputs in CentAUR are protected by Intellectual Property Rights law, including copyright law. Copyright and IPR is retained by the creators or other copyright holders. Terms and conditions for use of this material are defined in the End User Agreement. 


\section{CentAUR}

Central Archive at the University of Reading

Reading's research outputs online 


\title{
What influences business academics' use of the Association of Business Schools' (ABS) list? Evidence from a survey of UK academics
}

\author{
James T. Walker, International Business \& Strategy, Henley Business School at the \\ University of Reading \\ Evelyn Fenton, Leadership, Organisation \& Behaviour, Henley Business School at the \\ University of Reading \\ Ammon Salter, School of Management, University of Bath \\ Contact: a.j.salter@bath.ac.uk, corresponding author \\ Rossella Salandra, Imperial College Business School, Imperial College London
}

The development of the Association of Business Schools' (ABS) list in 2007 and its rapid adoption by UK business schools has had a profound effect on the nature of business and management academics' ways of working. Using a large-scale survey of UK business academics, we assess the extent to which individuals use the Academic Journal Guide (AJG/ABS) list in their day-to-day professional activities. In particular, we explore how their perceptions of the list, the academic influence of their research, academic rank and organizational context drive the varied use. Building on prior research on the importance of univalent attitudes in predicting behaviour, we find those who have either strong positive or negative views of the list are more extensive users than those who are ambivalent. We also find that the extent of use of the AJG/ABS list is greatest among those academics who have lower academic influence, in the middle or junior ranks within Business Schools and in middle and low-status universities. We explore the implications of these findings for the value of journal rankings and for the management of business schools.

Key words: Association of Business Schools list, Academic Journal Guide, Research Assessment Exercise, journal rankings, academic attitudes and behaviour 


\section{INTRODUCTION}

In evaluating research quality there has been an observable shift internationally toward utilizing more rankings based appraisal methods as a means to measuring the quality of research, with these approaches being embedded in other methods of appraisal such as research assessment exercises (Coupé, Ginsbury and Noury, 2010; Hicks 2012). It is certainly the case that there is a widely held perception that rankings have become an intrusive element in academic life. However, the literature provides a rich set of rationales, both positive and negative, for the use of ranking mechanisms such as journal lists. Some view the diffusion of ranking lists as a malicious development, which further exacerbates the tendency in academic life towards greater managerialism, undermining academic integrity and leading to a stale, uniform research culture (Aguinis, Shapiro, Antonacopoulou, and Cummings, 2014; Starbuck, 2005; White, Carvalho, and Riordan, 2011; Winter, 2009). In contrast, others suggest that lists have become a critical device to enable efficient decision-making about research quality among a broad range of fields, assisting in activities such as promotions and hiring, workload arrangements, submissions to the research evaluation exercises, and allocating resources (Agrawal et al., 2011; Beattie and Goodacre, 2012; Giles and Garand, 2007; Reinstein and Calderon, 2006; Voss, 2010).

The embeddedness of lists within every sphere of academic life makes 
understanding academic's perceptions of journal lists important as part of wider discussions about the changing nature of universities, including the spread of the 'audit culture' to this domain (Craig, Amernic and Tourish, 2014). Given their perceived economic and social importance, universities have been subject to greater levels of attention in terms of accountability and assessment from governments and students (Antonelli and Fassio, 2016). Assessing the quality and quantity of the research generated has become important to influencing the relationship between the economic resources directed towards universities and the amount of knowledge generated (Auranen and Nieminen, 2010; Hicks 2012). This discourse linking academia to the international competitiveness of countries is supported by the New Public Management ideology (Hood, 1995), of which the UK, (including Australia and New Zealand) is regarded as a pacesetter (Lapsley, 2009). Lists are more broadly used in social sciences, and to some extent the humanities, than science where bibliometrics have a more dominant role. The role of audit and assessment mechanisms such as journal rankings may therefore be seen as a specific case of the market-focused philosophy impacting public institutions generally (Craig et al, 2014).

UK universities have been absorbing managerialist public sector trends since the Jarrat Report (1985) and are now part of the "audit explosion" (Power, 1994, 1997) affecting all public-sector agencies. This audit explosion has two features common to all agencies as outlined by Lapsley (2009), first there is the preoccupation with target setting. As a result, universities have been accused of 'gaming' the Research Excellence Framework in terms of numbers of staff submitted (Stern Review, 2016), lobbying for journals to be included in journal lists such as the Financial Times 45 (Craig, et al, 2014) and the practice of individual academics to target journal outputs (Hussain, 2013). Second is the compliance mentality resulting from target setting, which may 
lead to perverse and dysfunctional behaviour (Gendron, 2008; Whitley, 2000) and reduced intrinsic motivation (Morris, 2006), thereby weakening engagement.

The case of business schools is of interest to this debate as these are multidisciplinary institutions of significance within the university due to Business and Management academics making up a significant proportion of staff and providing substantial income (Piercy, 2000). They also operate under the shadow of a wide range of rankings and accreditation systems, which shape their ability to attract students and other resources. In this way business schools are in the forefront of the wider trends impacting how universities are managed and business school journal lists provide an insight into how one aspect of evaluation is perceived and shapes the behaviour of academics. This raises questions like: What factors lead academics to use journal lists more extensively? What role does the context in which individuals work and their personal circumstances have on the extent of list use?

Our study is informed by the literature on individual academics and institutional rankings (Easton and Easton, 2003; Gendron, 2008; Gillies, 2012; Harman, 2000; James, 2011; Knowles and Michielsens, 2011; Manna, 2008; Moed, 2007; Morris et al., 2011; Northcott and Linacre, 2010; Oswald, 2007; Piercy, 2000), the psychology of planned behaviour (Ajzen, 1988) as well as attitude strength (Conner and Sparks, 2002; Thompson et al; 1995) and the specific contextual features of business schools (Butler et al, 2015; Hussain, 2015). To examine our research questions in detail, we draw upon four different sources of data, including a large-scale survey of academics working at UK business schools. The survey mainly, but not exclusively, focused on the Academic Journal Guide (AJG)/Association of Business Schools (ABS) list, from here on referred to as the AJG/ABS list. The reason for this is that, while the AJG/ABS list is one of a number of rankings, it is by far the most extensively used ranking 
instrument in the UK with over 89 per cent of academics working in business schools in the UK saying they use this list (Walker et al., 2015). Linking this data to information on websites, the Research Excellence Framework (REF) census, and individuals' publication records in Scopus, we explore the predictors of academics' extensive use of the journal list in terms of their individual and contextual factors. The analysis is based on both a descriptive account as well as several generalised least squares models.

INDIVIDUAL AND INSTITUTIONAL FACTORS DETERMINING USE OF THE AJG/ABS LIST

University research in the UK is evaluated through six yearly audits entitled 'research selectivity exercises', the most recent being entitled the Research Excellence Framework (REF). In Business and Management, the REF is based on peer review.

the quality of individual papers submitted to the REF is increasingly perceived by academics to be evaluated through the outlets in which they are published through journal ratings lists (Broadberry and Pidd, 2016). The most prevalent of these lists was produced (as the ABS list) by the now retitled (following Royal Charter) Chartered Association of Business Schools and renamed the Academic Journal Guide (AJG) in 2015. The AJG/ABS list began life as a list of all the journals from which three or more articles were submitted to the business and management panel of the RAE in 2001 . Other journals were then added through comparison with lists from six UK business schools (Morris et al., 2010). The list, by explicitly consolidating UK institutional lists, reduced the relevance of institution specific lists with Aston's 2008 list being one of the last formal lists of its type and was derived using both metrics and "expert opinion" of scholars representing sub-disciplines within business and management.

It must be said that the UK context is not alone in the development of journal lists. Harzing (2017) provides a continuously updated 'list of lists', which consolidates 
attempts in Australia, the US, France, Denmark among others to provide rankings of journals in business and management. In some cases, lists are mandated by official governmental research bodies, such as the Centre national de la recherche scientifique in France. In other cases, they have been developed by associations (Australian Business Deans Council) or specific institutions (Erasmus Research Institute of Management list in the Netherlands). That lists and journal metrics are used so extensively outside the context of the particular national context in the UK in itself highlights the broader impact of lists as a component of the "audit society" in academia demonstrating a diffusion effect (Morris and Lancaster, 2005).

Much of the debate about academic journal lists in general, and the AJG/ABS list in particular, has focused on the detail of their construction and development. Concerns have been raised about explicit and implicit biases against certain subject areas, most notably accounting (e.g. Hoepner and Unerman 2012, Hussain 2011, Morris et al. 2011) and to a lesser extent retail (Findlay and Sparks, 2010) and human resource management (Stewart, 2005). In our analysis, we have been careful to incorporate subject area differences.

Anecdotal evidence suggests that this list is commonly used in UK business schools for hiring, probation and promotion decisions. While it was the case that different institutions used a combination of evaluation methods such as the citation metrics and peer review, it is nevertheless clear that in preparing their REF 2014 submissions, institutions relied heavily on the 'ABS list' as a proxy for the sub-panel's likely assessment (By et al., 2013). Indeed, anecdotal accounts are corroborated by evidence from a large-scale survey used in this study where $89.2 \%$ of participants perceived that their business school used the list "to decide which individuals to submit to the Research Excellence Framework (REF)" (Walker et al., 2015) despite the 
requirement by the REF panel itself to avoid the use of any journal list and instead to rely strictly on peer review (Broadberry and Pidd, 2016).

The use of journal lists by UK business schools has also been critically scrutinized. As a consequence of their 'one size fits all' logic, it has been argued, journal lists condition the research activity of academics by suppressing the diversity of topics and methods thereby constricting innovation and critique (e.g., Adler and Harzing, 2009; Alvesson and Sandberg, 2013; Lawrence, 2008; Macdonald and Kam, 2007; Northcott and Linacre, 2010). In addition, the use of journal rankings has been thought to create a sort of 'list fetishism' in which the journal assumes a greater importance than the content of the paper (e.g. Hussain, 2015; Mingers and Willmott 2013; Willmott 2011). Alternatively, the use of journal lists has been defended by those who see them as a generally accepted means of ranking journals by academics (Morris, et al., 2009; Rowlinson et al, 2011; Rowlinson et al, 2015) and much of the literature also notes the acceptance and promotion of journal lists by academic managers such as Deans (Agyemang and Broadbent, 2015; De Rond and Miller, 2005; MacDonald and Kam, 2007; Mingers and Willmott, 2010; Willmott, 2011). A recent bibliometric analysis suggests that journals with high rankings in lists are more supportive of innovative, interdisciplinary, and diverse papers, but tend to favour more quantatitive methods than lower ranked journals (Vogel, et al. 2017). However, little empirical research has revealed academic's attitudes towards the use of lists. Most surveys of league tables and ranking systems have focused upon the views of senior managers and leaders (see Hazelcorn, 2007, 2008, 2009). Where academics have been consulted, such as in Harley's (2002) survey of social science and business related disciplines in the aftermath of 2001 RAE, this showed staff hostility towards the exercise but attitudes towards and use of specifically journal lists are largely unknown. 
Given the divergent views on the AJG/ABS list, we sought to develop a neutral survey instrument, with questions that allowed respondents to express both positive and negative views about the list and its impact on their working practices. To this end, we were careful to review the prior literature on the negative and positive effects of the AJG/ABS list, as well as the wider context of the assessment of research quality. Thus, the statements were chosen and adapted from previous literature discussing the advantages and disadvantages of journal guides (e.g., Willmott 2011).

While we may intuitively expect that those who have a positive view of lists are more likely to use them in a variety of professional circumstances than those with a negative view, the literature from psychology provides a different perspective based on the importance of social conformity and attitude strength as influences on behaviour (Fishbein and Ajzen, 1975). In general, the use of journal lists may be explained by the theory of planned behaviour (Ajzen 1988), whereby perceived behavioural control determines both intentions and behaviour. In terms of scholarly publishing and other professional decisions, descriptive norms (Rivis and Sheeren, 2003) may be important as these are perceptions of significant others' own attitudes and behaviours in the domain. Here the opinions and actions of significant others provide information that people use in deciding what to do themselves (e.g., if the Research Dean is targeting the list then it must be the necessary/good thing to do).

The theory also suggests that attitudes are more predictive of subsequent behaviour if they are more univalent than ambivalent (Conner and Sparks, 2002). Ambivalence may arise as a result of internal conflict within individuals between their own academic values and institutionally required behaviour (strong institutional norms) in response to journal rankings (Agyemang and Broadbent, 2015), leading to inactivity by individuals. 
Hypothesis 1. Academics who exhibit strong views towards the AJG/ABS list (either positive or negative) will display a greater likelihood to use this list compared to those who are more ambivalent to the list.

Academic influence tends to be highly skewed, with a small number of faculty typically, those who have developed the skills or networks to enable them to effectively meet the requirements of leading journals - accounting for the majority share of published papers and citations (Seglen, 1992, Baum 2011, Baum 2012). Scholars with high academic citations and that have experience at publishing at the highest level are typically well versed in determining the 'value' of particular journals. In contrast, those scholars with few citations and with a more modest set of writing projects are liable to carefully target their research in domains where they are most likely to be successful. They are inclined to rely on 'cues' from journal lists about viable outlets for their research (De Rond and Miller, 2005; Malsch and Tessier, 2015). It is also the case that while journal lists are occasionally adjusted, the majority of journals do not change their position and, where they do, the adjustment is typically upward. Thus, more experienced publishing scholars are less likely to need to access ranking lists as extensively as those who are less experienced in the publishing game. Hence we argue, Hypothesis 2: The greater an individual's academic influence, the lower will be their use of the AJG/ABS list.

While not the sole criteria, for most universities, promotion requires a significant contribution to knowledge, evidenced by a sustained record of publication (Becher, 1989; Merton, 1973). The emphasis on research outputs differs across stages of academic careers. Specifically, in the early and mid-career stages there tends to be a strong emphasis on meeting expectations for research outputs, leading scholars in their earlier careers to place more emphasis on publications over other aspects of their job 
role (Becher 1989, Jacobs and Winslow 2004). It may be that mid-career academics are hungry for information on which academic outlets to target if they are at a point where they wish to experiment by submitting work in different fields than their own area of expertise. Alternatively, they may be looking to find ways to increase the perceived quality of their outputs by targeting journals up the rankings ladder; or they may need to consult journal lists more regularly due to higher initial rejections from journal editors as they learn to refine their work to make it attractive to differing academic communities. In contrast, professors, who have reached the apogee of the academic career ladder, can be expected to be more knowledgeable about the publication process and less interested in conforming to expectations about where to publish. As a result of seniority, these professors may also have a greater willingness to overlook exhortations to publish in particular outlets by local research managers, and also to head off a significant threat to their position within an organization. Thus,

Hypothesis 3: Professors will use the AJG/ABS list less than mid-rank and junior scholars.

The landscape of UK Business Schools is diverse, but all institutions are subject in various ways to research evaluation. For example, the QS World University Rankings are largely based on relative research and employer reputation, and citation performance. In addition, teaching-based rankings, such as the Financial Times MBA ranking or the Guardian's University Guide, also incorporate research performance in their composite measures of institutional 'quality'. Yet, it is clear that the REF plays a central role in status ranking among UK business schools. This is not simply based on allocation of research income, it is also about the relative position of a school in relation to others. 
Building on the notion of middle-status conformity (Asch 1951; Phillips and Zuckerman, 2001), we expect that use of the list is greatest among business schools in the middle of the status distribution. This is because in high status institutions the reference group for comparison is partly non-UK, such as leading North American or continental European institutions. In addition, high status institutions can draw on local subject matter experts to guide them about journal status and therefore they may be less inclined to adhere by the AJG/ABS list itself. At the other end of the spectrum, individuals working at low research status institutions may be disengaged from the wider publication game. Indeed, individuals at these organizations may be detached from the formal requirement to publish research at an international level, instead focusing their efforts on teaching and local engagement and research. These individuals may also lack the resources, networks and skills to obtain these publications, and therefore withdraw from the 'race for publications'. However, for those individuals working at middle status business schools, the desire to match the requirements and expectations of the higher status organizations is liable to be great. In this context, individuals themselves may possess sufficient resources, networks and skills to aspire to publish at an international level. Moreover, their local context may be keen to support their efforts, hoping to obtain the status benefits associated with successfully participating in the REF. In addition, local research managers may include expectations for the REF into promotion, hiring and resourcing decisions, further reinforcing individual's own predilections to engage in the status competition.

Hypothesis 4: The status of an academic's institution will be curvilinearly related (inverted $U$-shaped) to their use of the AJG/ABS list, such that academics at high and low-status institutions are likely to utilize the list less extensively than those working in middle status institutions. 


\section{METHODS}

\section{Data and Sample}

The context for our study is the population of academics working at UK business schools in the period immediately following the REF 2014. Our research approach combines information from four independent sources: (1) business schools' websites, (2) the REF census, (3) publication data and (4) a large-scale survey. ${ }^{1}$

The initial stage of the data collection involved capturing data from UK universities' business school websites that included gender and academic rank. These details were gathered at three points in time. The initial collection was made directly prior to the 2014 REF census in late 2013; the second round was conducted the following year where email addresses were also captured and the data were finally updated in 2015, when all researchers' names and contact details were double-checked on the web to ensure they were as accurate and current as possible. The second source was the REF census. This included the REF scores and individual research outputs. Third, to capture information on publications, we matched our data on faculty with individual's publication information that was obtained from Elsevier's Scopus. The searches of authors' records and downloading their publications were performed in July 2014 using the 'author preview' function in Scopus. These data were then manually checked, utilising information from websites and other sources. We also employed ranking data taken from the AJG/ABS list (AJG 2015).

The final element in the study was a large-scale survey conducted in 2015 (see also Salter et a. 2017). The survey data used came from a larger research project examining the ways business academics' view journal lists as a method of research

\footnotetext{
${ }^{1}$ This paper builds on a larger research project on business academics attitudes towards assessment systems, including impact with non-academic audiences (Salter et al. 2017).
} 
assessment. As an element of this inquiry, we administered an on-line questionnaire to all academics working in business schools that were included in RAE 2008, with the addition of University College London. In order to ensure clean records for the survey, we attempted to remove individuals who were not expected to be potentially research active. Thus, the participants' list included Senior Teaching fellows but excluded Teaching Associates/Teaching fellows, Visiting, Honorary, Emeritus faculty, and PhD students. The final population analysed was made up of 8,002 academics from 90 UK business and management schools.

The survey was designed iteratively. First, we assembled questions from prior studies and then developed our own bespoke questions. We then piloted the survey with more than 20 business and management scholars, the majority of whom were based outside the UK but had recently worked at UK universities. Based on the results of the pilot, we adjusted the text of the questions and then re-ran the pilots with a smaller group of faculty. The survey was open for one month, and non-respondents were asked to participate three times. In total, we received responses from 1,945 participants, leaving us with a response rate of just over $24 \%$.

As part of the project, we linked the survey data with public information from business school websites. To do this, we followed a several stage protocol to ensure the de-identification of the data, as was explained to respondents on the project website. First, we replaced the personal names and institutional affiliation information in the survey data with a randomly assigned token number, an approach called pseudonymisation. Second, we created another set of random tokens for the individual names and institutional affiliations to be used to capture information about individuals from their publications and REF data. Third, we linked the two sets of tokens via separate files. All files were also individually password protected and held on secure 
servers. This approach ensured that the survey data and other personal information were never combined on a single file, and therefore the data used for analysis contains no personal identifying information.

In order to check the reliability of the pool of responses, we undertook two approaches to identify potential bias in our sample. First, we compared the academic ranks of those who completed the survey against the overall sample, distinguishing between institutions' ranking in REF using their overall Grade Point Average (GPA). Given the exclusion of teaching fellows from the population, the sample included a slightly higher percentage of professors and a greater proportion of staff from the top twenty ranked institutions. Second, we checked the primary expertise of survey participants in order to indicate a broad correspondence between survey participants and those who were submitted to REF 2014. To do so, the proportion of REF outputs was compared to the expertise of participants who completed the survey using the subject classifications used in the AJG 2015. Overall, the sample was consistent with the broad section of papers submitted to the REF. After excluding responses for nonitem answers and completing matching across the various sources of data, we were left with a sample of 1,009 individuals for which we have full information on all the variables used in the analysis.

\section{Measures}

\section{Dependent variable}

The central concern of our study is the use that individual academics make of the AJG/ABS list and how extensively they use the list in activities shaping their academic lives. The literature highlights at least seven distinct uses in their professional activities that are shaped by the list. Specifically, prior works suggest that a commonly cited use, deciding where academics should submit their papers is seen to be driven either by institutional 
forces such as encouragement by Deans or Research Directors (ABS 2010; Alvesson and Sandberg 2013; De Rond and Miller 2005; Harley et al 2004; Hussain, 2015; MacDonald and Kam, 2007; McNay, 2007; Mingers at al 2009; Parker, 2008; Rebora and Turri 2013; Willmott, 2011; Smith et al, 2011) or as a result of gamesmanship by academics in response to management control systems (Agyemang and Broadbent; 2015; Espeland and Sauder, 2007). For those whose research outputs meet the criteria defined by particular universities, career mobility and salary enhancement is the reward, therefore one might expect use of the AJG/ABS list when framing or assessing a promotion case (ABS 2010; Adler \& Harzing 2009; Harley et al. 2004; Morris et al 2009). Similarly, given the embedding of journal lists within academic discourse (Agyemang and Broadbent, 2015) the use of such lists to highlight personal accomplishments in an appraisal (Adler and Harzing 2009; Agyemang and Broadbent, 2015; Aspromourgos, 2012; Harley et al 2004; Hogler and Gross, 2009; Willmott, 2011) and within ones CV (ABS 2010; Agyemang and Broadbent, 2015; Clarke et, al, 2012; Harley et al 2004;) or when discussing one's own research with colleagues is seen to become more prevalent as use of the list becomes part of academic professional identities (Alvesson and Sandberg; 2013), with a powerful normative effect on professional practice (Morris, et al 2009; Willmott, 2011). The taken-for-granted nature of journal lists as a ranking measure and the redefinition of organisational scripts (Agymang and Broadbent, 2015) may lead academics to talk differently about key practices as professional identities become bound to such rankings (Hussain, 2015). These institutional and professional developments may lead to assessments of the research outputs of colleagues based on journal rankings (ABS 2010; Harley et al 2004; Morris et al, 2009; Rebora and Turri 2013; Willmott, 2011) or rankings based assessments when encouraging junior researchers to read a specific paper (Malsch and 
Tessier 2014). Accordingly, participants were asked to indicate how frequently they use the AJG/ABS List for each of the following activities: (1) "to decide where to submit papers"; (2) "to frame or assess a promotion case"; (3) "to highlight accomplishments in an appraisal”; (4) “within someone's Curriculum Vitae"; (5) "to judge the research outputs of other academics"; (6) "to encourage doctoral students or colleagues to read a specific paper"; and (7) "to discuss research with colleagues" [using a five-point scale listing 1. 'Never', 2. 'Rarely', 3. 'Occasionally/sometimes', 4. 'Almost every time', 5. 'Always']. Motivated by the work of Landis, Beal, \& Tesluk (2000) we took the mean score across the seven categories to capture the extent of use of the list in the analysis. ${ }^{2}$ Table I summarises the responses to the set of questions, noting the broad usage, and shows that the list shapes publications strategies, and how people frame their contributions and promotion cases. It also appears to be used by a significant share of academics to help judge the work of other academics, while a sizable minority also use the list when discussing their research with colleagues.

\section{<TABLE I ABOUT HERE>}

\section{Independent variables}

The survey asked a number of questions enabling participants to provide their views of the AJG/ABS list. Specifically, they were asked to indicate their level of agreement with the following six negative statements drawn from the literature in relation to the AJG/ABS list: "Shifts research efforts away from debates that researchers would like to contribute to" and "Fosters a 'research monoculture"" (Clarke et al, 2012; Mingers and Willmott, 2010; Rafols et al, 2012; Van Fleet et al, 2000; Willmott, 2011). "Encourages researchers to focus on issues that are only of interest to other academics

\footnotetext{
${ }^{2} \mathrm{We}$ also tested the reliability of the construct by use of factor analysis however we did not find that our results were altered but that the goodness-of-fit measures supported our use of the mean measure.
} 
rather than practitioners/policy-makers" (Adler and Harzing, 2009) "Promotes 'low risk' research", and "Leads to 'technically well-executed but boring research" (Adler and Harzing, 2009; Lawrence, 2008; Macdonald and Kam, 2007), “Rewards journals that strive to 'imitate a US-oriented model of scholarship"' (Willmott, 2011). To provide a balanced view and also to ensure that respondents did not tick down the list, participants were also asked about their level of agreement with several positive or neutral statements in relation to the AJG/ABS list: "Helps research efforts to get recognized", "Helps researchers to make judgments about the quality of research being undertaken by a researcher in their field" "Motivates academics to try to achieve higher research quality", "Helps researchers to make judgments about the quality of research being undertaken by a researcher outside their field" (Baden-Fuller et al, 2000; Kelly et al, 2009; Morris et al, 2010; Morris et al, 2011). ${ }^{3}$ Participants responses to these points were classified on a five point scale expressed from "Strongly disagree", to "Strongly agree". To derive the independent variables negative views and positive views, we took the arithmetic mean of the negative and positive categories respectively. ${ }^{4}$ Table II summarises the responses to the set of questions.

\section{$<$ TABLE II ABOUT HERE>}

Academic influence. To proxy differences in how individual academic contribution influenced scholarship, we considered the researchers' total number of

\footnotetext{
${ }^{3}$ We excluded one question from the analysis as it could be interpreted as being a neutral statement. Specifically, that the AJG/ABS list "Encourages academics to be more targeted in where they publish their research".

${ }^{4}$ The separation between negative and positive views is justified theoretically but we also examined the validity of the construct using the Cronbach alpha metrics that indicated consistency within the measures by 0.85 (for the negative views construct) and 0.86 (for the positive views construct) but not between them (the Cronbach alpha being 0.45). Also, to help to ameliorate concerns that multicollinearity was influencing our finding we implemented a Variance Inflation Factor test that indicated that there is no issue of multicollinearity.
} 
citations, as indicated in their Scopus record, adjusting for their academic age, quantified as the number of years since the year of their first publication.

Academic rank. To assess academic rank, we relied on a survey question. Specifically, we asked respondents "What is your current position?". We then created three dummy variables professor, associate professor, and lecturer, coded three binary dummy variables when respondents selected "Professor/Chair", "Associate Professor/ Reader/ Senior Lecturer/ Senior Research Fellow/ Principal Research Fellow" or "Lecturer/ Assistant Professor/ Research Fellow/ Research Associate". To fill any gaps (e.g. relative to respondents who had not completed this question), we relied on the data collected from the business schools' websites.

Institutional research status. To address the institutions' research status, we considered their Grade Point Average (GPA) calculated from the REF Summary for Unit of Assessment 19 - Business and Management (overall rank of institution in REF 2014). We classified this into three groups: 1. High-status institutions ranked between 1 and 20: 2. Mid-status institutions ranked between 21 and 50, and 3. Low-status institutions those who were ranked over 50.

\section{Control variables}

At the level of the individual researchers we included in the model two additional demographic variables (gender and obtained PhD in the UK). Based on information gathered from the business schools' websites, we created a dummy variable equal to 1 for male and 0 for female academics. With respect to the $\mathrm{PhD}$ institution, we created a binary variable equal to 1 if the individuals had earned their $\mathrm{PhD}$ from a UK university, and 0 otherwise.

We also derived a variable indicating if the individual was included in the Research Exercise Framework (REF), following the data management protocol 
described above. The REF does not link individuals' names nor does it provide other information such as co-authorship, institution, or research group. In addition, in most instances individual's outputs are clustered, enabling us to use a mixture of fuzzy matching and manual checking to link publications to individuals in over $95 \%$ of instances.

We included Field dummies to consider any field-specific heterogeneity. This information was based on a survey question where we asked respondents to indicate their primary area of expertise using the subject classifications used in the Academic Journal Guide 2015. This includes 22 discipline areas.

Finally, we used a variable from the survey (based upon the literature) capturing the extent to which the individual perceives their institution uses the AJG/ABS list. The goal of this variable is to control for a potential spurious correlation between an individual's use and their institution's use of the list. In the survey participants were asked whether the Business School they work in used the AJG/ABS list for any of the following activities: "in its appraisal system"; "in deciding on a case for promotion"; "to provide financial rewards for individual research performance"; "to decide which individuals to submit to the Research Excellence Framework (REF)", "to determine workloads", "to determine access to internal funding", "to hire and recruit". We took the mean of the 'yes' or 'no' answers provided by the respondents. ${ }^{5}$

\section{RESULTS}

\footnotetext{
${ }^{5} \mathrm{We}$ also used exploratory factor analysis to identify dominant factors identifying two as capturing $72 \%$ of the total variance observed. However, we have utilised the variable that combines all seven categories as the dependent variable in the analysis that follows. The reason being that the goodnessof-fit measures were lower when the two-factor measure was applied, supporting the use of the sevencategory construct. That said, regardless of whether the two or seven variable construct was employed, we did not find the results were qualitatively altered.
} 
Descriptive statistics of the main and control variables are given in Table III. As Table I shows, the majority of the respondents $(66 \%)$ were male and (36\%) were Associate Professors. Pairwise correlations between the dependent variable and all the other variables are also included. The correlations between explanatory variables are not distinctly high.

\section{$<$ TABLE III ABOUT HERE $>$}

Table IV reports the results using a Generalised Least Squares and focuses on individual characteristics. In order to interpret the coefficients as marginal effects, we use a logarithmic transformation of the dependent variable. Model 1 tests Hypothesis 1 that argued that those who hold strong views of lists, either positive or negative, are likely to be more extensive users of the list. The results confirm this (positive and statistically significant coefficients for 'Positive' and 'Negative' views), moreover the magnitude of the coefficients suggest that the effect of stronger positive views on the use of the AJG/ABS list is higher than the effect of stronger negative views. Model 2 examines Hypothesis 2 that predicts that those with higher academic influence (ageadjusted life time citations) consult journal lists less extensively. The findings confirm that this is the case with an increase in academic influence leading to a reduction in the extensiveness of use of the AJG/ABS list. The results also supports Hypothesis 3 in that they consistently show that mid-rank (Associate Professors) and junior (Lecturers) scholars are likely to utilize the journal list more extensively than full Professors.

\section{$<$ TABLE IV ABOUT HERE $>$}

Table $\mathrm{V}$ expands the analysis to incorporate institutional effects, examining whether we observe greater use of the list among middle status institutions than high and low status ones. The results are partially consistent with Hypothesis 4. We find that 
academics in mid-status and low-status institutions are likely to utilize the AJG/ABS list more extensively than those in high-status institutions.

As expected, we find that there is a strong correlation between the institutional use of the AJG/ABS list and the extent of use of the list by individuals. However, it is noteworthy that comparing the coefficient from Table $\mathrm{V}$ there is no qualitative change in the findings when including this variable.

In Model 2 and Model 3 (labeled Robustness 1 and 2), we test the extent to which the findings are robust to the inclusion of alternative measures of academic influence than lifetime citations. First, we measured the Scopus's Source Normalised Impact Factor (SNIP) Journal weighted outputs for each individual, based on data from 2008-2012, the last data available prior to the REF process. The findings show that this alternative metric, while correctly signed, is not statistically related to the use of the list. Second, we derived a measure of AJG/ABS weighted outputs. Again, this alternative measure of academic influence is not a robust correlate with the use of the list. Overall, the findings emphasize that the different conceptualizations of academic influence have differing outcomes on the extent that the ABS ranking is used.

\section{$<$ TABLE V ABOUT HERE >}

In addition, we find evidence that academics who have obtained their $\mathrm{PhDs}$ in the UK are more extensive users of the list. Finally, we capture differences in disciplines. The survey indicated that the majority (over $60 \%$ surveyed) of academics considered that the AJG/ABS list was not "consistent across all fields". Also - perhaps not surprisingly, given that business and management is an umbrella of subjects rather than a defined discipline - the list has been adopted unevenly, where disciplines such as accounting, economics and finance embraced academic rankings much earlier and more extensively than others (Adler and Harzing, 2009). We do find evidence of 
differences with Business History, General Management, Ethics and Social Responsibility and Social Sciences, all using the list less extensively than other subjects within business and management. We also find that women use the list less extensively than men, perhaps reflecting their being less well served by them (Özbilgin, 2009).

\section{DISCUSSION}

Univalent (strong) attitudes are shown to be highly predictive of behaviour (Connor and Sparks, 2011) in contrast to ambivalent (weak) attitudes resulting from conflicting perceptions held of an issue or object where loose cognitive associations in memory creates a lack of bias leading to behavioural inconsistencies towards the issue or object (Bargh et al, 1992; Bassili, 1996; Lavine et al, 1992). As ambivalent attitudes are relatively unstable over time, they are weaker predictors of behaviour than univalent attitudes (Lavine, et al, 1998). What is interesting about our findings is that both positive and negative univalent attitudes correlate with extensive use of journal lists (although unsurprisingly the positive views are held by the most extensive users). The extensive use of journal lists in professional practice by academics with univalent negative views may be explained by the influence of social norms whereby culture and administrative procedures of their business school make the use of lists both normative (use in CVs and staff discussions) (Willmott, 2011) and mandatory (use in appraisal and promotion) (Agyemang and Broadbent, 2015). Therefore academics with lower academic influence and lower academic rank will use journal lists as a vehicle for increasing reputation and promotion (Butler and Spoelstra, 2012, 2014; Macdonald and Kam, 2007; Mingers and Willmott, 2010; Tourish and Willmott, 2015; Willmott, 2011). There is a nuance to our findings in that they show that the different conceptualizations of academic influence have differing outcomes on the extent that the ABS ranking is used. A plausible reason is that our measure is aged adjusted lifetime citations as this provides a long-run measure of academic influence measuring the 
extent of an academic's work used. In contrast, of the journal ranking based measures, one is constrained to the REF window, and is thus a shorter run measure. However, we acknowledge that, as far as we are aware, there is little research that examines how scholars conceive the difference between journal rankings and citations, or the extent that some individuals may trade-off between citations and rankings.

The institutionalization of journal lists such as the AJG/ABS list within business schools has a highly socializing effect upon behaviour regardless of strong negative views held by individual academics (Agyemang and Broadbent, 2015). The use of the AJG/ABS list is linked to the desire for promotion and advancement in career for younger academics who know the REF 'game' having studied in the UK and who wish to demonstrate influence by targeting top journals (De Rond and Miller, 2005; Malsch and Tessier, 2014; Mingers and Willmott, 2013; Willmott, 2011). Hence the finding of the strong link between extensive list use and extrinsic motivation for being an academic. Ambivalent attitudes are associated with least use of journal lists, explained by the mismatch between cognition and emotions leading to inaction. Ambivalence could be the result of ambivalent attitudes within academics' work environment (views and behaviours held by significant others are not strong) thereby having little socializing effect upon list use.

Individual use of the list may also relate to the status of their institution, given that our findings show clear differences between extensive journal list use and the rankings of Business Schools. We found that both mid and lower status institutions (2150 and greater than 50) make more use of the AJG/ABS than high-status institutions ranked 1-20. For high-status business schools which use the journal list the least, their reputation has been established over a long period of time and they will have already attracted academic staff with good reputations. For these organizations, the set of target 
journals is fairly well established and limited in number. These institutions are liable to follow international expectations for business schools, such as the UTDallas list of journals or the FT list, rather than align themselves with national norms. The mid-status institutions who use journal lists most extensively wish to be ranked according to academic performance and move into the high-status positions, of which utilizing the AJG/ABS list is perceived as a significant feature. In contrast to the top institutions, the mid-status business schools view each incremental increase in rank as an achievement to be broadcast to alumni, students and staff and it is where one would expect to find the fiercest competition for reputation as there is both much to lose and gain.

A key purpose of journal ranking lists like the AJG/ABS list is to act as a tool to help shape and inform decision-making about research performance. It is proposed as a way of enabling researchers to target quality journals (Kelly et al, 2009; Morris et al, 2009; Morris et al, 2011) and thereby acts as a mechanism to attach value to research conducted within business schools. However our research exposes a deeper undercurrent of what is valued within business schools as indicated by the profile of those who use the AJG/ABS list most extensively. It confirms that the powerful institutionalizing effects of the AJG/ABS list upon academics in business schools (Willmott, 2011) has greatest resonance with early to mid-career researchers within low and middle ranked institutions. Here the AJG/ABS list is used extensively for a wide variety of professional activities by academics who are both positive and hostile towards the list. These academics also exhibit greater extrinsic motivation in their work. This profile supports many critical discussions in the literature on journal rankings which note the gradual shift in academic values from a concern with freedom of intellectual endeavour to an instrumental pursuit of highly ranked journals that trumps research foci and intellectual interest (Agyemang and Broadbent, 2015; Alvesson and 
Sandberg, 2013; Harley, 2002; Hussain, 2015). This "gradual readjustment" has been discussed by Butler and Spoelstra (2014) who note that academics may be compelled to participate in list use despite being hostile to the principles of the AJG/ABS list and in such a way that submission patterns are changed to target journals which may be less appropriate for their work. Extensive list use as shown by our survey reinforces not only individual norms, but also institutional norms of behaviour as a gradual culture of gamesmanship develops (De Rond and Miller, 2005; Mingers and Willmott, 2013; Willmott, 2011). There then follows perceptions of professional identity by academics that are wholly intertwined with the AJG/ABS list, a critical point made by Hussain (2015) and Nkomo (2009) who note that such professional sunk costs make any critique of journal lists unacceptable.

We would therefore expect the acceptance of these new academic values to be more nearly complete, since Harley's (2002) survey following the 2002 RAE. As Harley noted, while academics were divided over research selectivity, they were united in compliance with perceived demands - a behavioural imperative which has no doubt solidified changes to professional identity such as the use of ranking lists over the last 30 years, since the first research assessment exercise in 1986. Our research shows these new academic values are most entrenched in the middle and low ranked institutions and enacted by junior and mid-career researchers, particularly those with UK PhDs, who will set the norms of professional engagement for future generations of researchers. The socialising effect of targeting lists for publication as part of these values is not to be underestimated, shaping as it does, the research strategy of young academics. ${ }^{6}$ While Harley focused on the co-opting of peer review for managerial ends, the use of the

\footnotetext{
${ }^{6}$ We contacted the Chartered Association of Business Schools who pointed out that PhD student registrations are common suggesting this mechanism may indeed be an important one.
} 
AJG/ABS list for almost every significant professional practice by academics may be seen to have a similar impact in directing research priorities and academic goals.

\section{CONCLUSIONS}

This research has heeded the call by Hussain (2015) for further in-depth surveys of academic attitudes to lists to be conducted. It would seem that the use of AJG/ABS list is greatest among early and middle stage academics working in low and middle status business school organizations. Here the perception is of a pervasive use of the AJG/ABS list. Moreover, it is clear that strong opinions of the list - both positive and negative - shape its use. Greater indifference to the list arises from seniority and membership of elite (top 20) research status institutions. Only academics within elite UK Universities can partly insulate themselves from the auditing effects of national journal lists, although they may be subject to pressure from international lists or metrics.

Although it is common among business and management faculty to be critical of the AJG/ABS list, the list itself is a product of a wider shift in research assessment towards more formal, measurement based methods of assessment, as part of a reorientation to the 'audit' society (Power, 1997). This pattern is widespread across academic sectors and in different national contexts. In part, it is driven by the desire by governments to make research systems more 'accountable' in various ways to the publics that fund them. It is also part of the growth of rankings, lists and league tables by public and private actors, trying to specify the status of different higher education institutions and departments against each other across a wide range of criteria. Indeed, the widespread use of these rankings by the higher education institutions themselves for promotion and performance assessment helps to create a self-reinforcing cycle of institutionalization. The growth of these assessment systems may also stem from the 
increasing availability and computational power of metrics for research assessment themselves. The case of business and management in the UK could be seen to represent an extreme case, where the patterns observed in other domains are magnified due to the institutionalization of 'the list' by powerful actors within the system and its 'acceptance' by members of the profession.

It is also clear that there are a wide range of lists of journals in circulation, and each of these lists imposes a hierarchy upon research assessment. Even if the AJG/ABS list did not exist, research managers would have access to other lists, such as the FT list or UTDallas list, and tools, such as journal citation rankings, to rank the quality of an individual's outputs against others. Moreover, the wide availability of research measures at the institutional, journal and individual level make it difficult to return to a 'pre-list' era where research assessment was conducted largely by peer review. It is also not clear that traditional peer review of research assessment, provides a 'purer' form of assessment given the inherent biases and structures of peer review itself. For example, the REF peer review typically relies on the views of a small number of individuals, working in confidence. The particular interests, background or biases of these individuals and how these shape the assessment process are unknown. In other countries, such as Italy, it is possible to obtain information about the reviewer scores for individual research outputs and explore whether the backgrounds of the assessor themselves shape the nature of the assessment (Geuna and Piolatto, 2016).

What is perhaps unique to business and management in the $\mathrm{UK}$ is the pervasiveness of the use of the AJG/ABS list across a wide range of institutions. Within less than 10 years since its development, the AJG/ABS list has become embedded and institutionalized, creating a self-reinforcing cycle of use and attention by faculty, research managers and external actors. As it stands the AJG/ABS list remains a 
lightning rod for a range of critiques of the broader range of changes in the higher education sector, in general, and business schools, in particular. We hope by providing new, rich information we have been able to help inform this debate by bringing some evidence about who uses these lists, helping to open a wider conversation about their (de-)merits. In this vein, it is our hope that in exposing the increasing institutionalisation of the AJG/ABS list, we preserve the professional autonomy of academics to engage in reflexive critique.

There are several limitations to our research approach. First, our study deals with perceptions towards and use of the AJG/ABS list and the systematic evaluation of how the process was actually managed would make a potentially interesting contribution to the literature. Second, our study is based on a survey of academics at a single point in time. We are unable to say how the use of the list changes individuals' behavior or attitudes, since we have only a snapshot of these views. Greater processual research is required to understand how the use of, or attitudes about, the list shape subsequent behavior and attitudes. Third, we have focused on the AJG/ABS list rather than research assessment in general. It is not clear whether the results we found would apply equally or differently to peer review based forms of research assessment, such as the REF. Morever, our study does not focus on institutional practices of research assessment, but rather individual's perceptions of these practices. Future research could explore the relationship between how institutions assess research and how individual academics perceive these assessments, examining incongruities between the formal practices and the views of the individuals subject to them. Fourth, our approach focuses on business and management researchers, and therefore we are unable to comment on how other fields of research respond to metrics. Future research could explore inter-subject differences in attitudes to metrics and lists. Fifth, we do not explore how key actors 
may be responsible for diffusing the use of the list, for example by academics moving between institutions. Finally, although we have attempted to provide a 'neutral' approach to the use of the AJG/ABS list, drawing upon the literature that sees positive and negative aspects of this list, such attempts at 'neutrality' may disguise latent biases among the research team about the nature of the list itself. We hope that in making our research approach clear, we can encourage others to continue this line of research in the future, building a richer understanding of how the use of journal lists is shaped by attitudes, personal characteristics and institutional context.

By bringing attention to the perceptions and uses of journal lists by academics themselves, we hope to help inform wider debates about the merits or demerits of these lists, and how these assessment mechanisms are understood, used and shaped by the academics upon which they are imposed. 


\section{REFERENCES}

Antonelli, C., and Fassio, C. (2016) Academic knowledge and economic growth: are scientific fields all alike?. Socio-Economic Review, 14(3): 537-565.

Asch, S.E. (1951). Effects of group pressure on the modification and distortion of judgments. In H. Guetzkow (Ed.), Groups, leadership and men (pp. 177-190). Pittsburgh, PA: Carnegie Press.

Auranen, O., and Nieminen, M. (2010). University research funding and publication performance. An international comparison', Research Policy, 39: 822-834.

Association of Business Schools (2010). Academic Journal Quality Guide. London, Chartered Association of Business Schools.

Adler, N. J., and A.-W. Harzing (2009). When knowledge wins: Transcending the sense of and nonsense of academic rankings', Academy of Management Learning and Education, 8(1), pp.72-95.

Agrawal, V.K., Agrawal, V., and M. Rungtusanatham (2011). 'Theoretical and interpretation challenges to using the author affiliation index method to rank journals', Production and Operations Management, 20(2), pp.280-300.

Aguinis, H. Shapiro, D. L. Antonacopoulou, E. P. and T.G. Cummings (2014). 'Scholarly Impact: A Pluralist Conceptualization', Academy of Management Learning and Education, 13(4), pp.623-639.

Agyemang, G. and J. Broadbent (2015). 'Management control systems and research management in universities: An empirical and conceptual exploration', Accounting, Auditing and Accountability Journal, 28(7), pp.1018 - 1046.

Ajzen, I. (1988). Attitudes, Personality and Behavior._Chicago, Illinois: The Dorsey Press.

Alvesson, M. and J. Sandberg (2013). Constructing Research Questions: Doing Interesting Research, Los Angeles, CA: Sage.

Aspromourgos, A. (2012). The managerialist university: an economic interpretation. Australian Universities' Review, 54(2), pp.44-49.

Baden-Fuller, C., Ravazzolo, F. and T. Schweizer (2000). 'Making and Measuring Reputations: The Research Ranking of European Business Schools', Long Range Planning 33(5), pp.621-650

Bargh, J. A., Chaiken, S., Govender, R., F. Pratto (1992). 'The generality of the automatic attitude activation effect', Journal of Personality and Social Psychology 62(6), pp.893-912. 
Bassili, J. N. (1996). Meta-judgmental versus operative indexes of psychological attributes: The case of measures of attitude strength, Journal of Personality and Social Psychology, 71(4), pp.637-653

Baum, J.A., (2011). 'Free-riding on power laws: questioning the validity of the impact factor as a measure of research quality in organization studies', Organization, 18, pp.449-466.

Baum, J.A., (2012). 'The skewed few does "skew" signal quality among journals, articles, and academics?' Journal of Management Inquiry, 21, pp.349-354.

Beattie, V., Goodacre, A. (2012). 'Publication records of accounting and finance faculty promoted to professor: Evidence from the UK', Accounting and Business Research, 42(2), pp.197-231.

Becher, T., (1989). Academic tribes and territories - intellectual enquiry and the cultures of disciplines. Milton Keynes, The Society for Research into Higher Education and The Open University.

Butler, N. and Spoelstra, S. (2012). 'Your excellency', Organization, 19(6), pp.891903.

Butler, N. and Spoelstra, S. (2014). 'The regime of excellence and the erosion of ethos in critical management studies', British Journal of Management 25(3), pp.538550 .

Butler, N, Delaney, H. and S. Spoelstra (2015). 'Problematizing 'Relevance' in the Business School: The Case of Leadership Studies', British Journal of Management, 26(4), pp.731-744.

By, R.T., Burnes, B. and C. Oswick (2013) 'Creating a leading journal and maintaining academic freedom', Journal of Change Management, 13(1), pp.1-8.

Clarke, C. A., Knights, D., and Jarvis, C. (2012). 'A labour of love? Academics in UK business schools', Scandinavian Journal of Management, 28, pp.5-15.

Conner, M. and Sparks, P. (2002). 'Ambivalence and attitudes', European Review of Social Psychology, 12, pp.37-70.

Coupé, T, Ginsburghy and A. Noury (2010). 'Are leading papers of better quality? Evidence from a natural experiment', Oxford Economic Papers 62, pp.1-11.

Craig, R., Amernic, J., and Tourish, D. 2014. Perverse audit culture and accountability of the modern public university, Financial Accountability \& Management, 30(1): pp.1-24.

De Rond, M. and A.N. Miller. (2005). 'Publish or perish bane or boon of academic life?', Journal of Management Inquiry 14(4), pp.321-329. 
Easton, G. and D.M. Easton (2003). 'Marketing journals and the Research Assessment Exercise', Journal of Marketing Management, 19, pp.5-24.

Espeland, W.N. and M. Sauder (2007). 'Rankings and Reactivity: How Public Measures Recreate Social Worlds', American Journal of Sociology, 113(1), pp.1-40

Findlay, A. and L. Sparks (2010). The UK Research Assessment Exercise (RAE2008) and retail research output, International Review of Retail, Distribution and Consumer Research, 20, pp.583-95.

Fishbein, M., and I. Ajzen (1975). Belief, attitude, intention, and behavior: An introduction to theory and research. Reading, MA: Addison-Wesley.

Gendron, Y. (2008). Constituting the academic performer: The spectre of superficiality and stagnation in academia, European Accounting Review, 17(1), pp.97127.

Geuna, A., and M. Piolatto (2016), Research assessment in the UK and Italy: Costly and difficult, but probably worth it (at least for a while), 45(1), pp.260-271.

Giles, M.W. and J. C., Garand (2007), Ranking political science journals: Reputational and citational approaches. PS: Political Science and Politics, 40(4), pp.741-51.

Gillies, D. (2012). 'Economics and Research Assessment Systems', Economic Thought 1, pp.23-47.

Harman, G., (2000). 'Allocating research infrastructure grants in post-binary Higher Education systems: British and Australian approaches', Journal of Higher Education Policy and Management 22, pp.111-126.

Harley, S. (2002). 'The Impact of Research Selectivity on Academic Work and Identity in UK Universities', Studies in Higher Education, 27(2), pp.187-205.

Harley, S., Muller-Camen, M. and A. Collin (2004), 'From academic communities to managed organisations: the implications for academic careers in UK and German universities', Journal of Vocational Behavior, 64, pp.329-45.

Hood, C. A. 1995. The NPM in the 1980s: Variations on a Theme, Accounting, Organizations and Society, 20(2-3): 93-109.

Hoepner, A.G.F., and J. Unerman (2012). "Explicit and implicit subject bias in the ABS journal quality guide.” Accounting Education, 21(1), pp. 3-15.

Hogler, R. and M.A. Gross (2009). 'Journal rankings and academic research: Two discourses about the quality of faculty work', Management Communication Quarterly, 23(1), pp.107-126.

Hussain, S. (2011). 'Food for thought on the ABS academic journal quality guide', Accounting Education 20(6), pp.545-559. 
Hussain, S. (2015). 'Journal list fetishism and the 'sign of 4' in the ABS guide: A question of trust?', Organization, 22(1), pp.119-138.

Jacobs, J. A., and S. E. Winslow (2004). 'The academic life course, time pressures and gender inequality', Community, Work \& Family 7(2), pp.143-161.

James, S. (2011). 'Does business school research have to be "excellent" to benefit business school teaching?', International Journal of Management Education 9(2), pp.37-47.

Kelly, A., Morris, H., and C. Harvey (2009). Modelling the outcome of the UK business and management studies RAE 2008 with reference to the ABS Journal Quality Guide', Association of Business Schools.

Knowles, D. and E. Michielsens (2011). 'Counting on an Iterative Process: Initial Lessons from the Research Assessment Exercise 2008', The Electronic Journal of Business Research Methods, 9(1), pp.47-56), available online a twww.ejbrm.com

Lavine, H., Thomsen, C. J., Borgida, E., and J.S. Sullivan (1992). 'A test of the single-versus dual-evaluation model of attitude accessibility', Annual Meeting of the Midwestern Psychological Association, Chicago.

Lavine, H, Thomsen, C, Zana, M, and E. Borgida (1998). 'On the primacy of affect in the determination of attitudes and behavior: The moderating role of affectivecognitive ambivalence', Journal of Experimental Social Psychology 34, pp.398-421

Lawrence P. (2008). 'Lost in publication: how measurement harm science', Ethics in Science and Environmental Politics, 8, pp.9-11.

Landis, R.S., Beal, D.J. and Tesluk, P.E. (2000). A comparison of approaches to forming composite measures in structural equation models, Organizational Research Methods, 3(2): 186-207.

Lapsley, I. (2009). New public management: The cruellest invention of the human spirit? Abacus, 45, 1: 1-21.

Macdonald, S. and J. Kam (2007). 'Ring a ring O' roses: Quality journals and Gamesmanship in Management Studies', Journal of Management Studies, 44, pp.640655.

Malsch, B., and S. Tessier (2015). 'Journal ranking effects on junior academics: Identity fragmentation and politicization', Critical Perspectives on Accounting, 26, pp. 84-98.

Manna, M. (2008). 'Assessing the Assessment or, the RAE and the Optimal Organization of University Research', Scottish Journal of Political Economy, 55(5), pp.637-653. 
McNay, I. (2007). 'Research assessment; researcher autonomy', Autonomy in Social Science Research: The View from United Kingdom and Australian Universities. International Perspectives on Higher Education Research, 4, pp.183-216.

Merton, R. (1973). The Sociology of Science: Theoretical and Empirical Investigations. Chicago, University of Chicago Press.

Mingers, J, Watson, K. and M.P. Scaparra (2009). 'Estimating Business and Management Journal Quality from the 2008 Research Assessment Exercise in the UK', Kent Business School working Paper Series, 205, pp.1-49.

Mingers, J, and H. Willmott (2010). 'Moulding the one-dimensional academic: The performative effects of journal ranking lists', Kent Business School Working Paper Series: 239.

Mingers, J. and H. Willmott (2013). 'Taylorizing business school research: On the 'one best way' performative effects of journal ranking lists, Human Relations, 66(8), pp.1051-1073.

Moed, H.F. (2007). 'The future of research evaluation rests with an intelligent combination of advanced metrics and transparent peer review', Science and Public Policy, 34(8), pp.575-83.

Morris, H., Harvey, C., A. Kelly (2009). 'Journal rankings and the ABS Journal Quality Guide.', Management Decision, 47, pp.1441-51.

Morris, H., Harvey, C., Kelly, A., and M. Rowlinson (2011). 'Food for thought? A rejoinder on peer-review and RAE2008 evidence', Accounting Education, 20(6), pp.561-573.

Morris, T. and Lancaster, Z. (2005) Translating Management Ideas, Organization Studies, 27(2): 207-233.

Nkomo, S. M. (2009) 'The Seductive Power of Academic Journal Rankings:

Challenges of Searching for Otherwise', Academy of Management Learning and Education 8(1): 106-12.

Northcott, D., and S. Linacre (2010). 'Producing spaces for academic discourse: The impact of Research Assessment Exercises and journal quality rankings', Australian Accounting Review, 20(1), pp.38-54.

Oswald, A.J. (2007). 'An examination of the reliability of prestigious scholarly journals: Evidence and implications for decision-makers', Economica, 74, pp.21-31.

Özbilgin, M. (2009) 'From Journal Rankings to Making Sense of the World', Academy of Management Learning and Education 8(1), 113-21.

Parker, J., (2008). 'Comparing research and teaching in university promotion criteria', Higher Education Quarterly 62(3), pp.237-251. 
Phillips, D.J. and E.W. Zuckerman (2001). 'Middle status conformity: Theoretical restatement and empirical demonstration in two markets,' American Journal of Sociology, 107, 379-429.

Piercy, N. (2000). 'Why it is fundamentally stupid for a business school to try to improve its Research Assessment Score', European Journal of Marketing, 34, pp.2736.

Power, M. (1994) The Audit Explosion, Demos.

Power, M. (1997). The Audit Society: Rituals of Verification, Oxford University Press, New York.

Rafols, I., Leydesdorff, L., O’Hare, A., Nightingale, P., and A. Stirling (2012). 'How journal rankings can suppress interdisciplinary research: A comparison between innovation studies and business \& management', Research Policy, 41, pp.1262-1282.

Rebora, G. and M. Turri (2013). 'The UK and Italian research assessment exercises face to face', Research Policy, 42, pp.1657-1666.

Reinstein, A. and T.G. Calderon (2006). 'Examining accounting department's rankings of the quality of accounting journals', Critical Perspectives on Accounting, 17, pp. 457-90.

Rivis, A. and P. Sheeren (2003). 'Descriptive norms as an additional predictor in the theory of planned behaviour: A Meta-Analysis', Current Psychology: Developmental, Learning, Personality, Social, 22(3), pp.218-233.

Rowlinson, M., Harvey, C., Kelly, A., and H. Morris (2011). 'The use and abuse of journal quality lists', Organization, 18, pp.443-446.

Rowlinson, M., Harvey, C., Kelly, A., Morris, H., and E. Todeva (2015). 'Accounting for research quality: Research audits and the journal rankings debate', Critical Perspectives on Accounting, 26, pp.2-22.

Salter, A., Salandra, R. and Walker, J., (2017). 'Exploring preferences for impact versus publications among UK business and management academics', Research Policy, 46: pp. 1769-1782.

Seglen, P.O. (1992). 'The skewness of science', Journal of the American Society for Information Science 43, pp.628-638.

Smith, S., Ward, V., and A. House (2011). "Impact' in the proposals for the UK's Research Excellence Framework: Shifting the boundaries of academic autonomy', Research Policy, 40, pp.1369-1379.

Starbuck, W.H. (2005). 'How much better are the most prestigious journals? The statistics of academic publication', Organization Science, 16, pp.180-200. 
Stern, N. (2016) Independent Report: Research Excellence Framework Review, Department for Business, Energy and Industrial Strategy, 28 July.

Stewart, J. (2005). 'The UK research assessment exercise', Human Resource Development International, 8(4), pp.489-94.

Thompson, M.M., Zanna, M. P., and D.W. Griffin (1995). Let's not be indifferent about (attitudinal) ambivalence. In Petty, Richard E. and Krosnick, Jon A. (Eds). Attitude strength: Antecedents and consequences: 361-386. Hillsdale, NJ, US: Lawrence Erlbaum Associates, Inc, xx, 510 pp.

Tourish, D., and Willmott, H. 2015. In defiance of folly: Journal rankings, mindless measures and the ABS guide. Critical Perspectives on Accounting, 26, pp. 37-46.

Van Fleet, D.D, McWilliams, A. and D.S. Siegel (2000). 'A Theoretical and Empirical Analysis of Journal Rankings: The Case of Formal Lists', Journal of Management 26(5), pp. 839-861.

Voss, C. (2010). 'Reflections on the state of OM', POMS Chronicle, 17(1), pp. 1112.

Walker, J.T., Salter, A., and R. Salandra (2015). 'Initial Findings from the Survey of UK Business Academics 2015', Report to Survey Participants.

White, K., Carvalho, T., and S. Riordan (2011). 'Gender, power and managerialism in universities', Journal of Higher Education Policy and Management, 33, pp.179-188.

Whitley, R. (2000) The Intellectual and Social Organization of the Sciences, $2^{\text {nd }}$ edition, Oxford: Oxford University Press.

Willmott, H., (2011). 'Journal list fetishism and the perversion of scholarship: reactivity and the ABS list', Organization, 18, pp.429-442.

Winter, R. (2009). 'Academic manager or managed academic? Academic identity schisms in higher education', Journal of Higher Education Policy and Management, 31, pp. 121-131.

Vogel, R. Hattke, F. and Petersen, J. (2017). 'Journal rankings in management and business studies: What rules do we play by?', Research Policy, 46, pp. 1707-1722. 
